Preprint

UCRL-JC-137080

\title{
Extinction and Autoignition of $n$-Heptane in Counterflow Configuration
}

\author{
R. Seiser, H. Pitsch, K. Seshadri, W.J. Pitz, H.J. Curran
}

This article was submitted to

Twenty-Eighth International Symposium on Combustion, Edinburgh, Scotland, July 30-August 4, 2000

\section{January 12, 2000}

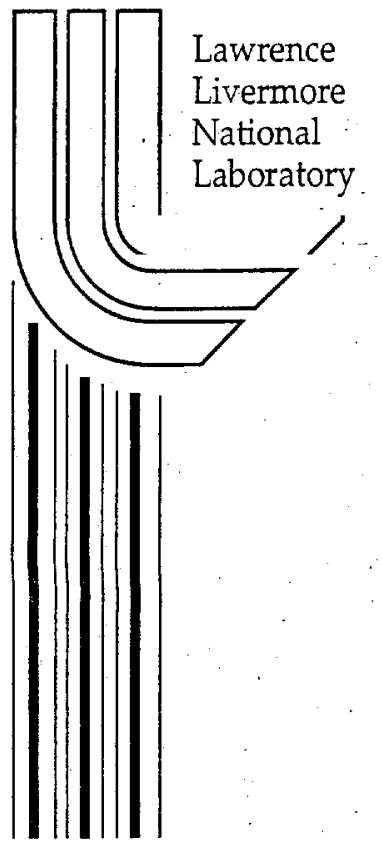




\section{DISCLAIMER}

This document was prepared as an account of work sponsored by an agency of the United States Government. Neither the United States Government nor the University of California nor any of their employees, makes any warranty, express or implied, or assumes any legal liability or responsibility for the accuracy, completeness, or usefulness of any information, apparatus, product, or process

disclosed, or represents that its use would not infringe privately owned rights. Reference herein to any specific commercial product, process, or service by trade name, trademark, manufacturer, or otherwise, does not necessarily constitute or imply its endorsement, recommendation, or favoring by the United States Government or the University of California. The views and opinions of authors expressed herein do not necessarily state or reflect those of the United States Government or the University of California, and shall not be used for advertising or product endorsement purposes. 


\title{
Extinction and Autoignition of $n$-Heptane in Counterflow Configuration
}

\author{
R. Seiser, H. Pitsch, and K. Seshadri \\ Department of Mechanical and Aerospace Engineering \\ University of California at San Diego \\ La Jolla, California 92093-0411 \\ W. J. Pitz and H. J. Curran \\ Lawrence Livermore National Laboratory \\ P. O. Box 808 \\ Livermore, California 94551
}

Corresponding author:

K. Seshadri

Center for Energy and Combustion Research

Department of Mechanical and Aerospace Engineering

University of California at San Diego

La Jolla, California 92093-0411

Phone: (858) 534-4876. Fax: (858) 534-5354.

email: seshadri@mae.ucsd.edu

- Preferred colloquium topic: Laminar Flames.

- Word-Length

1. 275 lines of text (including references). Number of words $270 \times 14=3850$.

2. 1 equation. Number of equivalent words $1 \times 21=21$.

3. 8 figures. Number of equivalent words $8 \times 200=1600$.

Total number of words $\mathbf{5 5 0 0}$

- Preferred presentation: Oral

Prepared for Presentation at.

Twenty-Eighth International Symposium on Combustion

University of Edinburgh

Edinburgh, Scotland

July 30-August 4, 2000. 


\title{
Extinction and Autoignition of $n$-Heptane in Counterflow Configuration
}

\begin{abstract}
A study is performed to elucidate the mechanisms of extinction and autoignition of $n$-heptane in strained laminar flows under nonpremixed conditions. A previously developed detailed mechanism made up of 2540 reversible elementary reactions among 557. species is the starting point for the study. The detailed mechanism was previously used to calculate ignition delay times in homogeneous, reactors, and concentration histories of a number of species in plug-flow and jet-stirred reactors. An intermediate mechanism made up of 1282 reversible elementary reactions among 282 species and a short mechanism made up of 770 reversible elementary reactions among 160 species are assembled from this detailed mechanism. Ignition delay times in an isochoric homogeneous reactor calculated using the intermediate and the short mechanism are found to agree well with those calculated using the detailed mechanism. The intermediate and the short mechanism are used to calculate extinction and autoignition of $n$-heptane in strained laminar flows. Steady laminar flow of two counterflowing streams toward a stagnation plane is considered. One stream made up of prevaporized $n$-heptane and nitrogen is injected from the fuel boundary and the other stream made up of air and nitrogen is injected from the oxidizer boundary. Critical conditions of extinction and autoignition given by the strain rate, temperature and concentrations of the reactants at the boundaries, are calculated. The results are found to agree well with experiments. Sensitivity analysis is carried out to evaluate the influence of various elementary reactions on autoignition. At all values of the strain rate investigated here, high temperature chemical processes are found to control. autoignition. In general, the influence of low temperature chemistry is found to increase with decreasing strain. A key finding of the present study is that strain has more influence. on low temperature chemistry than the temperature of the reactants.
\end{abstract}

\section{Introduction}

Chemical-kinetic mechanisms that describe oxidation of $n$-heptane $\left({ }^{n}-\mathrm{C}_{7} \mathrm{H}_{16}\right)$ have been developed by numerous investigators [1-13]. $n$-Heptane is a primary reference fuel for octane rating in internal combustion engines. It has a cetane number of approximately 56 , which is similar to the cetane number of conventional diesel. Recently a comprehensive chemicalkinetic mechanism has been developed to describe combustion of $n$-heptane [10]. Numerical calculations were performed using this mechanism and the results were compared with experimental data obtained in flow reactors, shock tubes, and rapid compression machines. Here, chemical-kinetic mechanisms are assembled from this comprehensive mechanism and are used to describe extinction and autoignition of $n$-heptane in nonpremixed systems. The results are compared with experiments conducted in the counterflow configuration [12-14].

The present study is motivated by a need to develop chemical-kinetic mechanisms that can be used in computational fluid dynamic codes to model combustion and transport processes 
taking place in diesel engines. Combustion processes in diesel engines closely resemble nonpremixed systems. Previous experimental studies on autoignition were focussed on measuring ignition delay times in shock tubes [15] and rapid compression machines [16-18]. These studies were conducted on premixed systems and revealed various aspects of $n$-heptane autoignition and combustion. The present study addresses extinction and autoignition of $n$-heptane in counterflow nonpremixed systems where transport processes play an important role. Computational resources required for calculating aspects of autoignition in an one-dimensional counterflow configuration are significantly larger than those required in a homogeneous system. Large reaction mechanisms, such as those for $n$-heptane, need to be reduced to make the numerical problem tractable in one-dimensional configurations:

Lindstedt and Maurice [5] have developed a detailed chemical-kinetic mechanism for describing the oxidation of $n$-heptane. This mechanism has been tested by comparing numerical results with experimental data obtained in stirred reactors, counterflow nonpremixed flames, and premixed flames. This was one of the first attempts to develop a chemical-kinetic mechanism for $n$-heptane which can be applied to flames where transport processes are important, and to stirred reactors. This mechanism, however, did not address ignition and extinction of nonpremixed flames. Seiser et al. [12] calculated the structure and critical conditions of extinction of nonpremixed $n$-heptane flames and compared the results with experimental measurements. This study employed a chemical-kinetic mechanism which had been previously simplified by introducing ad-hoc approximations [8]. At given concentrations of the reactants, the calculated strain rate at extinction was found to be higher than that measured [12]. Here, critical conditions of extinction are calculated using mechanisms that are deduced from the comprehensive mechanism of Curran et al. [10] and the results are compared with experimental data shown in Ref. [12]. Experimental data for the critical conditions of autoignition of $n$-heptane in the counterflow configuration are given in the Ref. [13,14]. Using this experimental data, overall chemical-kinetic rate parameters that characterize the rate of one-step overall reaction between fuel and oxygen were obtained [14]. Here, critical conditions of autoignition are calculated using mechanisms that are deduced from the comprehensive mechanism [10] and the results are compared with experimental data shown in Refs. [13,14].

\section{Description of Experimental and Numerical Studies in the Coun- terflow Configuration}

Steady, axisymmetric, laminar flow of two counterflowing streams toward a stagnation plane is considered. Figure 1 shows a schematic illustration of the counterflow configuration employed in previous experimental studies [12-14] and in the present numerical study. In this configuration a fuel stream made up of prevaporized $n$-heptane and nitrogen is injected from one 


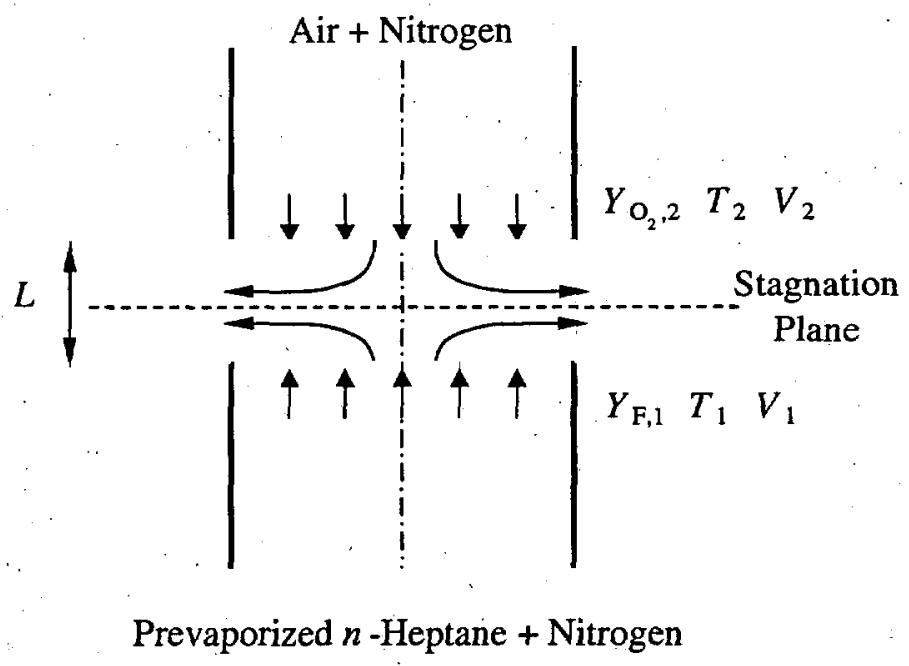

Figure 1: Schematic illustration of the counterflow configuration.

duct, called the fuel-duct, and an oxidizer stream made up of air and nitrogen is injected from the other duct, called the oxidizer-duct. These jets flow into the mixing layer between the two ducts. The exit of the fuel-duct is called the fuel boundary and the exit of the oxidizer-duct the oxidizer boundary. The mass fraction of fuel, the temperature, and the component of the flow velocity normal to the stagnation plane at the fuel boundary are represented by $Y_{F, i}$, $T_{1}$, and $V_{1}$, respectively. The mass fraction of oxygen, the temperature, and the component of the flow velocity normal to the stagnation plane at the oxidizer boundary are represented by $Y_{\mathrm{O}_{2}, 2}, T_{2}$, and $V_{2}$, respectively. The tangential components of the flow velocities at the boundaries are presumed to be equal to zero. The distance between the fuel boundary and the oxidizer boundary is represented by $L$.

In the experiments and numerical calculations the momenta of the counterflowing reactant streams $\rho_{i} V_{i}^{2}, i=1,2$ at the boundaries are kept equal to each other. Here $\rho_{1}$ and $\rho_{2}$ represent the density of the mixture at the fuel boundary and the oxidizer boundary, respectively. This condition ensures that the stagnation plane formed by the two streams is approximately in the middle of the region between the two boundaries. The value of the strain rate, defined as the normal gradient of the normal component of the flow velocity, changes from the fuel boundary to the oxidizer boundary [19]. The characteristic strain rate on the oxidizer side of the stagnation plane $a_{2}$ is presumed to be given by [19]

$$
a_{2}=\underset{L}{2\left|V_{2}\right|}\left(1+\frac{\left|V_{1}\right| \sqrt{\rho_{1}}}{\left|V_{2}\right| \sqrt{\rho_{2}}}\right)
$$


Equation 1 is obtained from an asymptotic theory where the Reynolds numbers of the laminar flow at the boundaries are presumed to be large [19]. Critical conditions of extinction are presumed to be given by the strain rate, $a_{2, e}$, the temperatures, and the mass fraction of fuel and oxygen at the boundaries. Critical conditions of autoignition are presumed to be given by the strain rate, $a_{2, \mathrm{I}}$, the temperature of the oxidizer stream, $T_{2, \mathrm{I}}$, the temperature of the fuel stream, and the mass fraction of fuel and oxygen at the boundaries. The experiments were conducted at a pressure of 1.013 bar.

\section{Experimental Procedure}

A detailed description of the burners is given elsewhere [12-14]. The flow rates of gases were measured by computer-regulated mass flow controllers. The velocities of the reactants at the boundaries were presumed to be equal to the ratio of their volumetric flowrates to the crosssection area of the ducts. The temperature of the fuel stream and the temperature of the oxidizer stream at the boundaries were measured using thermocouples. A brief description of the experimental procedure is given here.

\section{Critical Conditions of Extinction}

Extinction experiments were previously carried out allowing only small changes in the flame position in the reactive flow field [12]. It is convenient to express the flame position in terms of a conserved scalar quantity $\xi$, called the mixture fraction. The mixture fraction is so defined that $\xi=1.0$ in the fuel stream and $\xi=0$ in the oxidizer stream [20]. The location of the flamesheet, $\xi_{\text {st }}$, where the flux of the fuel and the flux of oxygen are in stoichiometric proportion, is given by $\xi_{\mathrm{st}}=\left[1+11 Y_{\mathrm{F}, 1} W_{\mathrm{O}_{2}} /\left(Y_{\mathrm{O}_{2}, 2} W_{\mathrm{F}}\right)\right]^{-1}$, where $W_{\mathrm{F}}$ and $W_{\mathrm{O}_{2}}$ represent the molecular weights of fuel and oxygen, respectively. Extinction experiments were performed keeping $\xi_{\text {st }}$ constant at 0.1. The temperature of the fuel stream $T_{1}=345 \mathrm{~K}$, and the temperature of the oxidizer stream $T_{2}=298 \mathrm{~K}$. The distance between the fuel boundary and the oxidizer boundary was $L=10 \mathrm{~mm}$. At some selected value of $Y_{\mathrm{O}_{2}, 2}$ the flame was stabilized at $a<a_{2, \mathrm{e}}$. The strain rate was increased by increasing $V_{1}$ and $V_{2}$ until extinction was observed. Experimental results are shown later.

\section{Critical Conditions of Autoignition}

Previous autoignition experiments were conducted with the mass fraction of prevaporized fuel, $Y_{F, 1}$, maintained at $0.387[13,14]$. The temperature at the fuel boundary, $T_{1}$, was $378 \mathrm{~K}$. The oxidizer stream was air with a mass fraction of oxygen $Y_{\mathrm{O}_{2,2}}=0.233$. The distance between the fuel boundary and the oxidizer boundary was $L=12 \mathrm{~mm}$. At a given strain rate and oxidizer temperature $T_{2}<T_{2,1}$ the flow field was established. The temperature at the oxidizer 
boundary was gradually increased until autoignition took place. Experimental results äre shown later.

\section{Formulation of the Numerical Problem}

The conservation equations of mass, momentum and energy and the species balance equations used in the formulation of the numerical problem are summarized elsewhere $[8,21,22]$. The species balance equations include thermal diffusion and the energy conservation equation includes radiative heat loss from carbon dioxide and water vapor [22]. Buoyancy is neglected. Calculations are performed over a computational domain of $10 \mathrm{~mm}$ to obtain the critical conditions of extinction and over a computational domain of $12 \mathrm{~mm}$ to obtain the critical conditions of autoignition. At both ends of the computational domain, the mass fractions of the reactants and the normal components of the flow velocity are specified. The values of the tangential component of the flow velocity at both ends are set equal to zero (the so-called plug-flow boundary conditions). Critical conditions of extinction are calculated with $T_{1}=345 \mathrm{~K}$ and $T_{2}$ $=298 \mathrm{~K}$. Critical conditions of autoignition are calculated with $T_{1}=378 \mathrm{~K}$. The characteristic strain rate at the stagnation plane is calculated using Eq. (1).

The chemical-kinetic mechanism used to calculate the critical conditions of extinction and autoignition is deduced from the comprehensive mechanism of Curran et al. [10]. This mechanism, 'called the detailed mechanism, comprises 2540 reversible elementary reactions among 557 species. The rate constant, $k$, of any elementary reaction in this mechanism is given by $k=B T^{n} \exp [-E /(\mathcal{R} T)]$, where $T$ is the temperature and $\mathcal{R}$ the gas constant. The frequency factor, $B$, the temperature exponent, $n$, and the activation energy, $E$, are the rate parameters. This comprehensive mechanism was previously used to calculate ignition delay times in homogeneous reactors, and concentration histories of a number of species in plug-flow and jetstirred reactors. The results were found to agree with experiments [10]. Improvements have been made to this mechanism [23]. Rate parameters for the forward rate constant of alkyl radical $\mathrm{R}$ addition to oxygen represented by the elementary reaction $\mathrm{R}+\mathrm{O}_{2}=\mathrm{RO}_{2}$ is now given by $B=4.52 \times 10^{12} \mathrm{~cm}^{3} /(\mathrm{mol} \cdot \mathrm{s}), n=0$, and $E=0$ for the primary, $B=7.54 \times 10^{12} \mathrm{~cm}^{3} /(\mathrm{mol} \cdot \mathrm{s})$, $n=0$, and $E=0$ for the secondary, and $B=1.41 \times 10^{13} \mathrm{~cm}^{3} /(\mathrm{mol} \cdot \mathrm{s}), n=0$, and $E=0$ for the tertiary alkyl radical. With the alkyl denoted by $R^{\prime}$, rate parameters for the forward rate constant of the reaction $\mathrm{R}^{\prime} \mathrm{O}_{2}+\mathrm{R}=\mathrm{R}^{\prime} \mathrm{O}+\mathrm{RO}$ is $B=7.00 \times 10^{12} \mathrm{~cm}^{3} /(\mathrm{mol} \cdot \mathrm{s}), n=0$, and $E=-4184 \mathrm{~J} / \mathrm{mol}$, for the reaction $\mathrm{RO}_{2}+\mathrm{HO}_{2}=\mathrm{RO}_{2} \mathrm{H}+\mathrm{O}_{2}: B=1.75 \times 10^{10} \mathrm{~cm}^{3} /(\mathrm{mol} \cdot \mathrm{s})$, $n=0$, and $E=-13702.58 \mathrm{~J} / \mathrm{mol}$, and for the reaction $\mathrm{RO}_{2}+\mathrm{R}^{\prime} \mathrm{O}_{2}=\mathrm{O}_{2}+\mathrm{RO}+\mathrm{R}^{\prime} \mathrm{O}: B$ $=1.40 \times 10^{16} \mathrm{~cm}^{3} /(\mathrm{mol} \cdot \mathrm{s}), n=-1.61$, and $E=7782.23 \mathrm{~J} / \mathrm{mol}$. Modifications in reaction rate rules are documented in Ref. [23]. Recent changes in the thermodynamic properties of peroxy radicals have been adopted $[24,25]$. 
The number of reactions and species in the detailed mechanism was reduced before it was used to calculate the critical conditions of extinction and autoignition in nonpremixed systems. To reduce the mechanism, ignition delay times, $\tau_{i g}$, in an isochoric homogeneous reactor configuration were calculated using the detailed mechanism. Ten conditions were selected given by values of initial pressure equal to 1 bar and 13.5 bar and values of initial temperatures equal to $625 \mathrm{~K}, 740 \mathrm{~K}, 909 \mathrm{~K}, 1176 \mathrm{~K}$ and $1667 \mathrm{~K}$. To test the influence of any given species on the ignition delay time, all elementary reactions in which this species appears were removed from the detailed mechanism and the values of $\tau_{\mathrm{ig}}$ were computed at the selected ten conditions using the truncated detailed mechanism now made up of 556 species. The deviation of the ignition delay time calculated using this truncated mechanism from the ignition delay time calculated using the detailed mechanism was obtained. If the deviation at all conditions was less than $0.84 \%$, this species was removed from the mechanism. Some species were retained in the mechanism even if the deviation was less than $0.84 \%$, because their influence on critical conditions of extinction and autoignition was suspected to be greater than their influence on $\tau_{\text {ig }}$ in homogeneous reactors. Using this procedure an intermediate mechanism made up of 1282 reversible reactions among 282 species was obtained. To reduce the mechanism further, the flame structure was calculated at one condition, and the structure of the reactive flow at two conditions close to autoignition. These calculations were made using the intermediate mechanism. The results were used to determine the important chemical paths of fuel breakdown and oxidation. Species that only appear along paths where the rates of fuel breakdown and oxidation are small were neglected from the intermediate mechanism. This gave a short mechanism made up of 770 reversible elementary reactions among 160 species. The intermediate mechanism and the short mechanism are available [26].

Figure 2 shows the ignition delay time, $\tau_{\mathrm{ig}}$, in stoichiometric mixtures of $n$-heptane-vapor and air as a function of the reciprocal of the initial temperature, $T_{u}$, for various values of pressure. All numerical results agree well with experimental data obtained in shock tubes [15] and in rapid compression machines [16]. Values of $\tau_{\mathrm{ig}}$ calculated using the short mechanism agree well with those calculated using the detailed mechanism. The agreement between values of $\tau_{\mathrm{ig}}$ calculated using the intermediate mechanism and the detailed mechanism is even better. A similar result was found when concentrations of key intermediate species including soot precursors were compared among the three mechanisms. The short and the intermediate mechanism are used to calculate the structure of the reactive flow-field in the counterflow . configuration and critical conditions of extinction and autoignition. 


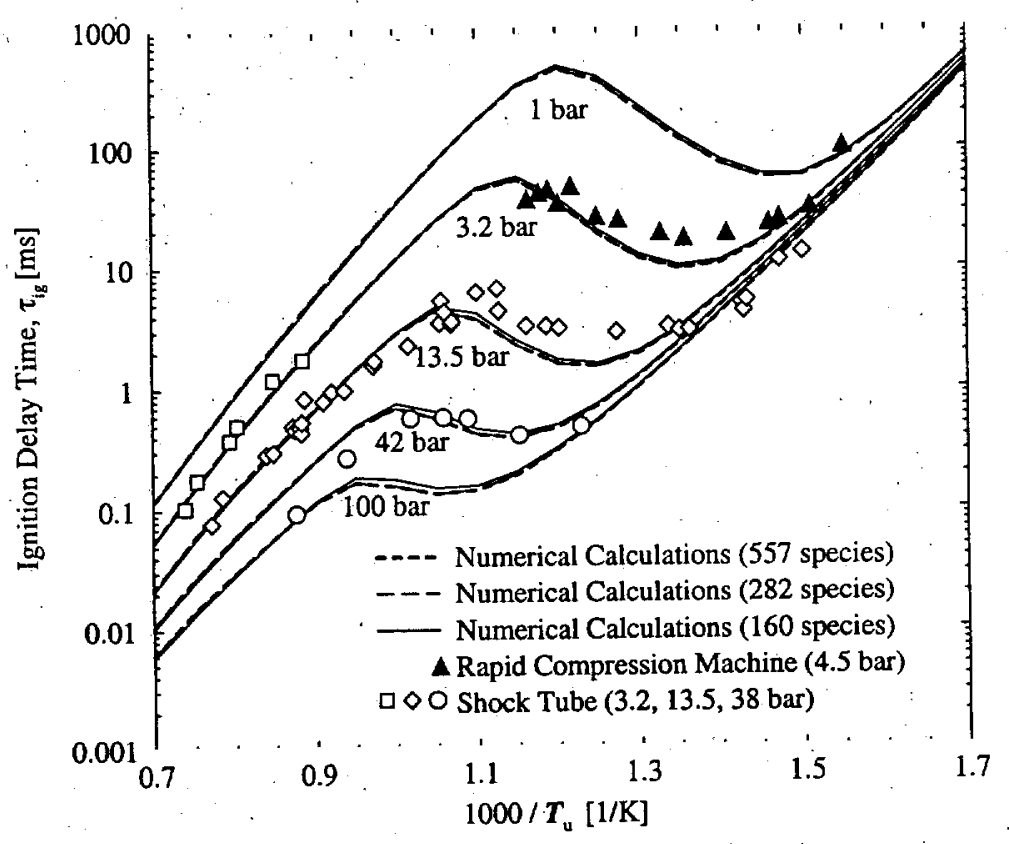

Figure 2: Ignition delay time, $\tau_{\mathrm{ig}}$, in stoichiometric mixtures of $n$-heptane-vapor and air as a function of the reciprocal of initial temperature, $T_{\mathrm{u}}$, for various pressures. The short-dashed line represents $\tau_{\mathrm{ig}}$ calculated using the detailed mechanism. The long-dashed line represents $\tau_{\mathrm{ig}}$ calculated using the intermediate mechanism. The solid line represents $\tau_{\mathrm{ig}}$ calculated using the short mechanism. The symbols represent experimental data obtained in shock tubes [15] and rapid compression machines [16]. 


\section{Extinction and Autoignition}

Figure 3 illustrates the procedure employed to deduce the strain rate at autoignition at a given value of $T_{2}$. The maximum temperature in the flow-field, $T_{\max }$, is plotted in Fig. 5 as a function of the strain rate. This figure is the so-called C-shaped curve. For values of

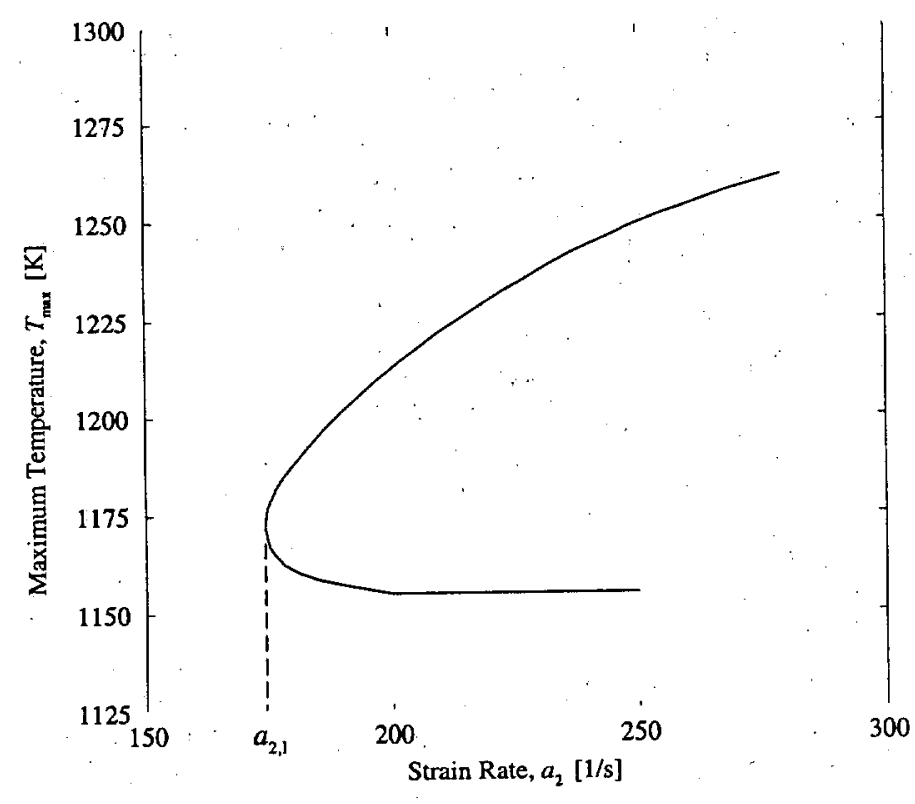

Figure 3: The maximum temperature, $T_{\max }$, as a function of the strain rate. Calculations are performed using the short mechanism for $T_{2}=1155 \mathrm{~K}$ and $T_{1}=378 \mathrm{~K}$. The mass fraction of fuel in the fuel stream is $Y_{F, 1}=0.387$.

strain rate greater than $a_{2, I}$ two solutions obtained are shown in Fig. 3. The solution with the lower value of the maximum temperature is stable, while the solution with the higher value of the maximum temperature is unstable. The quantity $a_{2, I}$ represents the strain rate at autoignition. A similar procedure is employed to obtain the critical conditions of extinction.

Figure 4 shows the mass fraction of oxygen in the oxidizer stream at extinction, $Y_{\mathrm{O}_{2}, 2}$, as a function of the strain rate, $a_{2, \mathrm{e}}$. The symbols represent measurements reproduced from Ref. [12]. Figure 4 shows the results of numerical calculations obtained using the short mechanism to agree well with those calculated using the intermediate mechanism. Numerical results agree well with experimental data. The agreement between the experimental data and numerical results shown in Fig. 4 is significantly better than that shown in Ref. [12].

Figure 5 shows the oxidizer temperature at autoignition, $T_{2, \mathrm{I}}$, as a function of the strain 


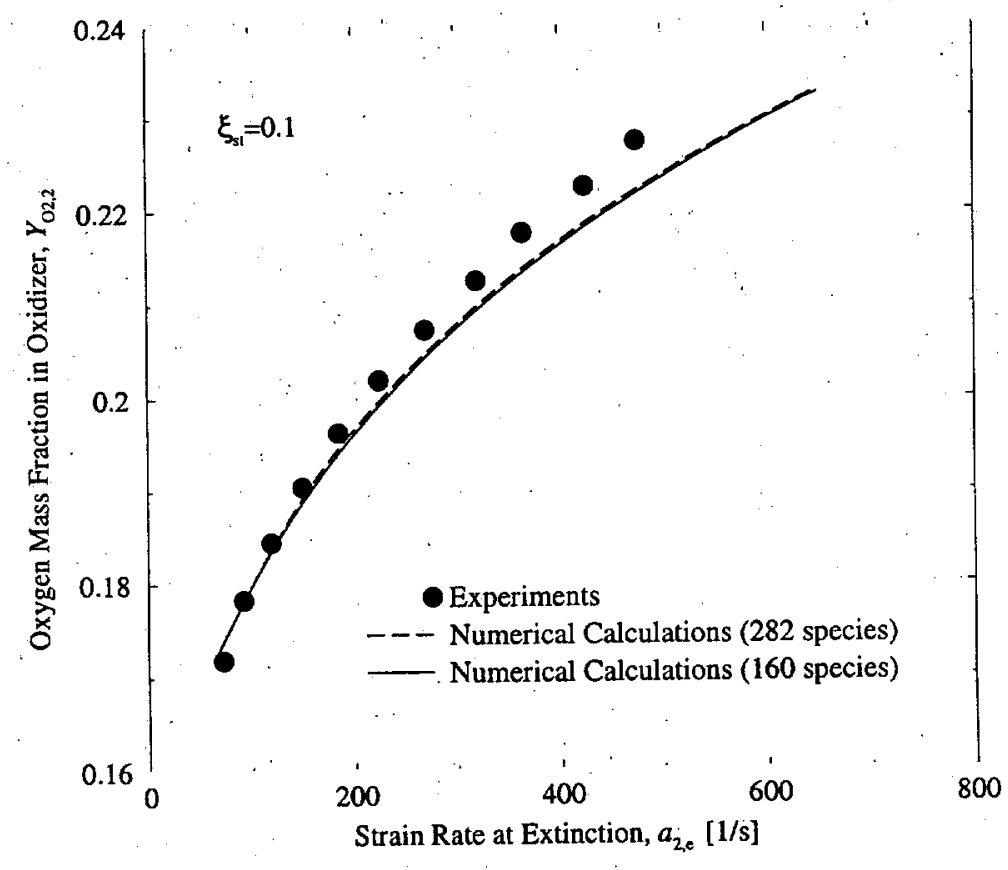

Figure 4: Mass fraction of oxygen in the oxidizer stream at extinction, $Y_{\mathrm{O}_{2}, 2}$, as a function of the strain rate, $a_{2, \mathrm{e}}$. The symbols represent measurements [12]. The solid line represents results of numerical calculations performed using the short chemical-kinetic mechanism. The dashed line represents results of numerical calculations performed using the intermediate chemical-kinetic mechanism. 
rate, $a_{2, \mathrm{I}}$. The symbols represent measurements reproduced from Refs. [13,14]. Figure 5

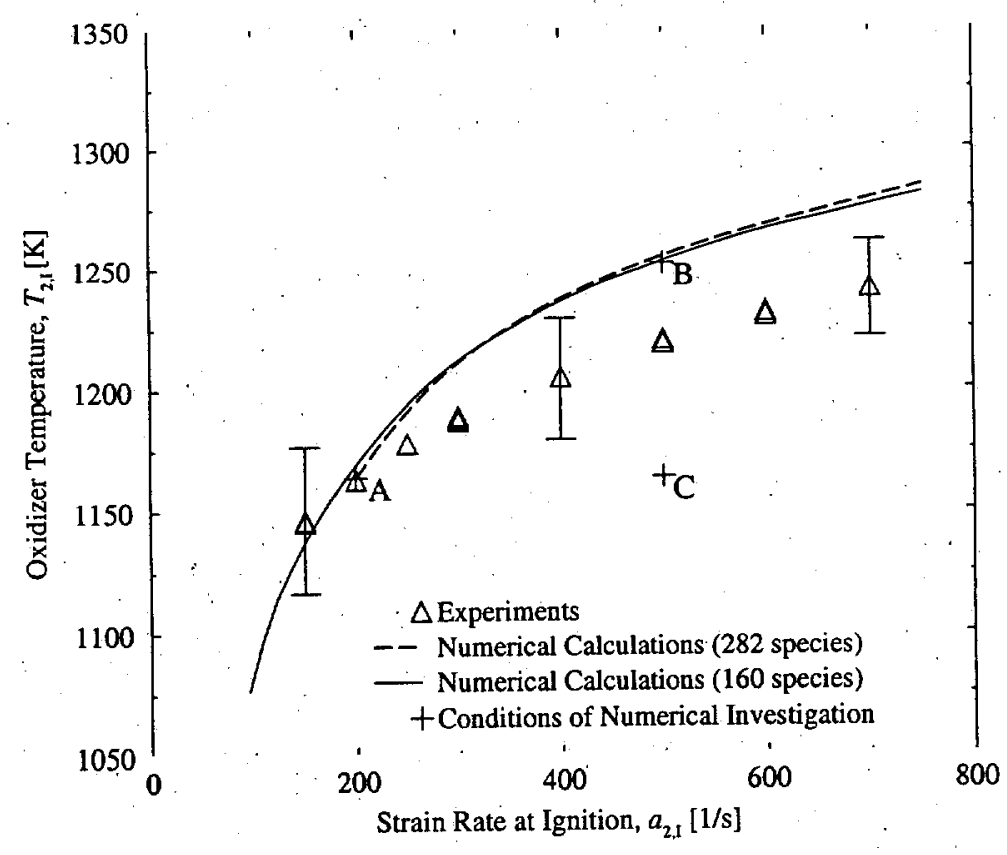

Figure 5: Oxidizer temperature at autoignition, $T_{2, \mathrm{I}}$, as a function of the strain rate, $a_{2, \mathbf{I}}$. The triangles represent measurements $[13,14]$. The solid line represents results of numerical calculations performed using the short chemical-kinetic mechanism. The dashed line represents results of numerical calculations performed using the intermediate chemical-kinetic mechanism. The plus symbols indicate conditions used in numerical investigation.

shows the results of numerical calculations performed using the short mechanism to agree well with those calculated using the intermediate mechanism. Numerical results agree well with experimental data at low values of the strain rate. At high values of the strain rate the numerical results show autoignition to take place at higher values of $T_{2, \mathrm{I}}$ in comparison to those measured. The plus symbols in Fig. 5 indicate the conditions used in numerical investigation.

\section{Influence of Strain on Autoignition}

Analysis was carried out to investigate the role of strain on autoignition. Numerical calculations were performed at three conditions identified here as case $A$, case $B$, and case $C$. Case A refers to calculations at $a_{2}=200 \mathrm{~s}^{-1}$ and $T_{2}=1164 \mathrm{~K}$, case B at $a_{2}=500 \mathrm{~s}^{-1}$ and $T_{2}=$ $1252 \mathrm{~K}$, and case $\mathrm{C}$ at $a_{2}=500 \mathrm{~s}^{-1}$ and $T_{2}=1164 \mathrm{~K}$. Calculations were performed using the short mechanism for $Y_{\mathrm{F}, 1}=0.387, T_{1}=378 \mathrm{~K}$, and $Y_{\mathrm{O}_{2}, 2}=0.233$. At $a_{2}=200 \mathrm{~s}^{-1}$, the calculated value of $T_{2, \mathrm{I}}=1165 \mathrm{~K}$, and at $a_{2}=500 \mathrm{~s}^{-1}, T_{2, \mathrm{I}}=1253 \mathrm{~K}$. Thus, case A and case 


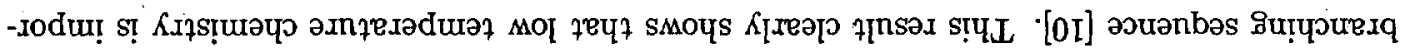

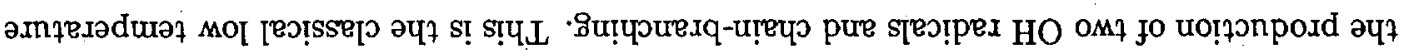

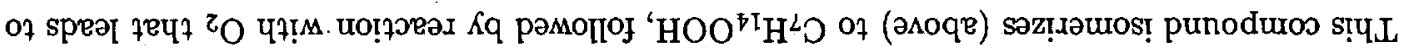

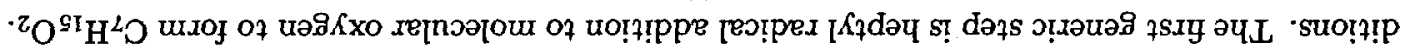

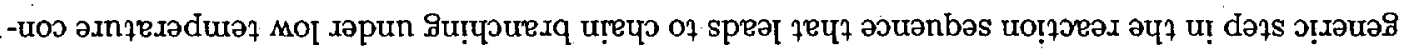

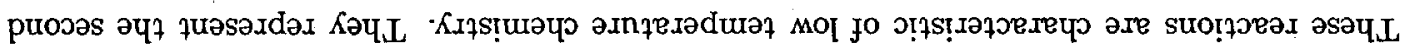

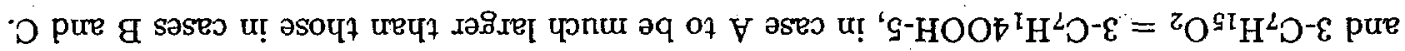

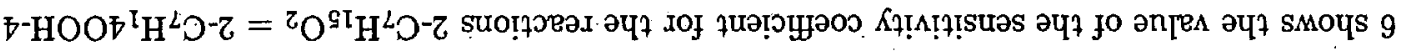

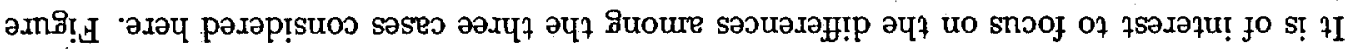

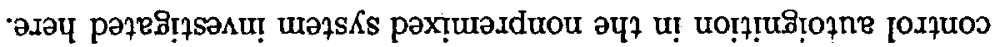

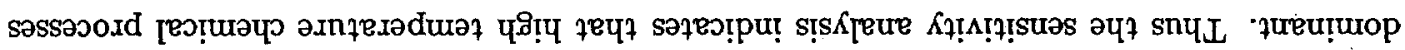

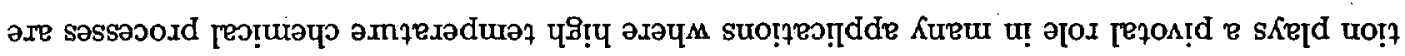

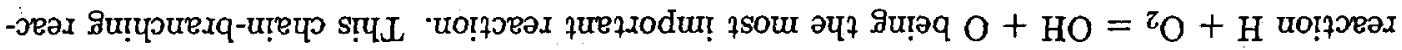

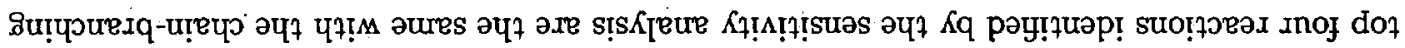

'E\&Z'0 $=z^{\prime 2}{ }_{X}$ pure '

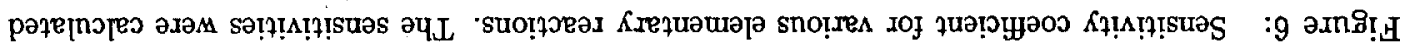

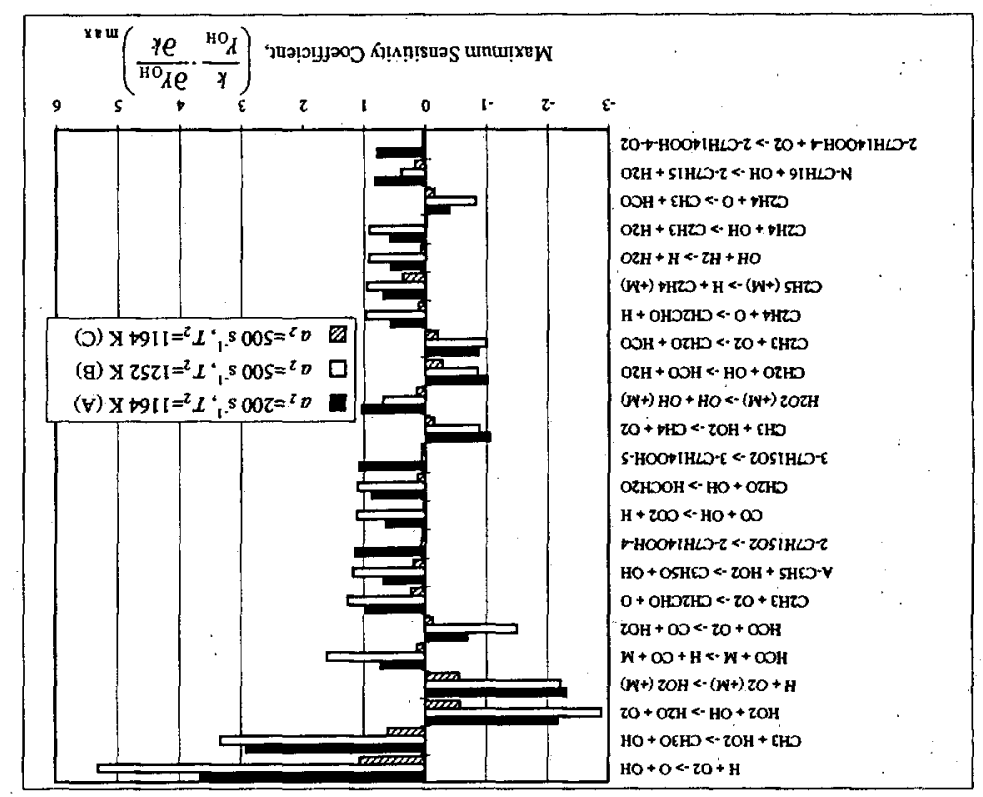

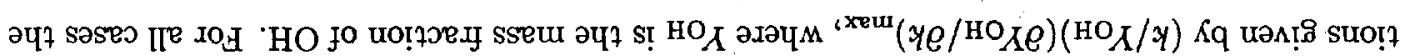

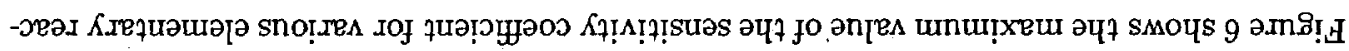

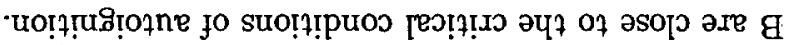


tant at low strain rates. Figure 6 shows that case $C$, which has the same value for $T_{2}$ as case A, does not exhibit low temperature chemistry. Thus, strain has a greater influence than oxidizer temperature on low temperature chemistry.

It is of importance to examine the influence of various reactions on the concentration of $\mathrm{OH}$ because it is the primary reactive radical produced by ignition reactions. It is also the primary radical that consumes the fuel and intermediate products under ignition conditions. Figure 7 shows profiles of various species calculated using the short mechanism at a condition close to autoignition (case A). Here distances are measured from the fuel boundary. The profile

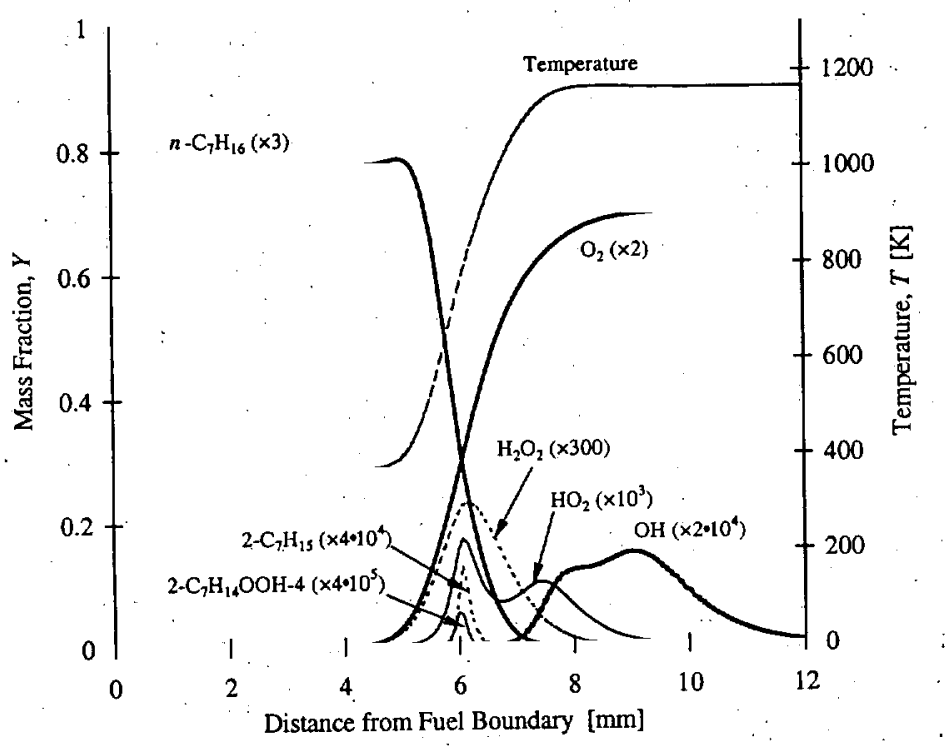

Figure 7: Profiles of temperature, $T$, and mass fractions of $\mathrm{C}_{7} \mathrm{H}_{16}, \mathrm{O}_{2}, 2-\mathrm{C}_{7} \mathrm{H}_{14} \mathrm{OOH}-5,2-\mathrm{C}_{7} \mathrm{H}_{15}$, $\mathrm{OH}, \mathrm{H}_{2} \mathrm{O}_{2}$, and $\mathrm{HO}_{2}$. These profiles are calculated using the short mechanism for $a_{2}=200, T_{2}=$ $1164 \mathrm{~K}, Y_{\mathrm{F}, 1}=0.387, T_{1}=378 \mathrm{~K}$, and $Y_{\mathrm{O}_{2,2}}=0.233$ (case A).

of $\mathrm{HO}_{2}$ shows an interesting double peak. The first peak is due to $\mathrm{HO}_{2}$ production from low temperature reaction paths given by $\mathrm{R}+\mathrm{O}_{2} \rightarrow \mathrm{RO}_{2} \rightarrow \mathrm{QOOH} \rightarrow$ alkene $+\mathrm{HO}_{2}$. Here $\mathrm{Q}$ represents $\mathrm{C}_{\mathbf{n}} \mathrm{H}_{2 n}$ species or structures. The second $\mathrm{HO}_{2}$ peak is due to high temperature paths leading to $\mathrm{HO}_{2}$, e.g. $\mathrm{HCO}+\mathrm{O}_{2} \rightarrow \mathrm{CO}+\mathrm{HO}_{2}$. The profile of $\mathrm{OH}$ shows a small peak around $6 \mathrm{~mm}$ followed by a large peak around $9 \mathrm{~mm}$ with a "shoulder" around $8 \mathrm{~mm}$. The shape of this profile is controlled by convection, diffusion, production, and consumption of $\mathrm{OH}$. From a detailed reaction path analysis, the main reactions that consume $\mathrm{OH}$ are found to be 
$\begin{array}{lll}\text { 1: } & n-\mathrm{C}_{7} \mathrm{H}_{16}+\mathrm{OH}=\mathrm{C}_{7} \mathrm{H}_{15}+\mathrm{H}_{2} \mathrm{O} & -45 \% \\ \text { 2: } & \mathrm{CH}_{2} \mathrm{O}+\mathrm{OH}=\mathrm{HCO}+\mathrm{H}_{2} \mathrm{O} & -13 \% \\ \text { 3: } & \mathrm{HO}_{2}+\mathrm{OH}=\mathrm{H}_{2} \mathrm{O}+\mathrm{O}_{2} & -7 \%\end{array}$

The main reactions that produce $\mathrm{OH}$ are

$$
\begin{array}{llr}
\text { 4: } & \mathrm{H}+\mathrm{O}_{2}=\mathrm{OH}+\mathrm{O} & 17 \% \\
\text { 5: } & \mathrm{CH}_{3}+\mathrm{HO}_{2}=\mathrm{CH}_{3} \mathrm{O}+\mathrm{OH} & 11 \% \\
6: & \mathrm{H}_{2} \mathrm{O}_{2}+\mathrm{M}=\mathrm{OH}+\mathrm{OH}+\mathrm{M} & 8 \% \\
7: & \mathrm{C}_{7} \mathrm{H}_{14} \mathrm{OOH}=\mathrm{C}_{7} \mathrm{H}_{14} \mathrm{O}+\mathrm{OH} & 14 \% .
\end{array}
$$

Here the percentages refer to the contribution of the specified reaction to production of $\mathrm{OH}$ integrated across the flow-field. Reaction 1 includes all reactions between $n$ - $\mathrm{C}_{7} \mathrm{H}_{16}$ and $\mathrm{OH}$ that give different isomers of $\mathrm{C}_{7} \mathrm{H}_{15}$, and reaction 7 includes all isomers of $\mathrm{C}_{7} \mathrm{H}_{14} \mathrm{OOH}$ and $\mathrm{C}_{7} \mathrm{H}_{14} \mathrm{O}$. The small peak in the profile of $\mathrm{OH}$ around $6 \mathrm{~mm}$ is due to production of this radical from low temperature reactions (e.g reaction 7 where a hydroperoxyheptyl radical produces a cyclic ether and an $\mathrm{OH}$ radical). This small peak occurs at $775 \mathrm{~K}$ which as shown in Fig. 2 is in the negative temperature coefficient region $(670-830 \mathrm{~K})$ of a stoichiometric $n$-heptane-air mixture in a homogeneous reactor at a pressure of $1 \mathrm{bar}$. At increasing distance from the small peak of $\mathrm{OH}$, the value of $Y_{\mathrm{OH}}$ begins to increase as the fuel is nearly consumed and intermediate species are formed. Prior to this point the mass fraction of $\mathrm{OH}$ is small because it reacts with the fuel via reaction 1. Later, formaldehyde and other intermediate hydrocarbon species such as ethene and propene disappear which leads to a further increase in the value of $Y_{\mathrm{OH}}$ for similar reasons. A number of reactions produce $\mathrm{OH}$ which includes its production from decomposition of $\mathrm{H}_{2} \mathrm{O}_{2}$ via reaction 6. Reaction path analyses at different locations show that this reaction gives the "shoulder" in the profile of $Y_{\mathrm{OH}}$ around $8 \mathrm{~mm}$. Reactions 4 and 5 make a significant contribution to the rates of production of $\mathrm{OH}$ around $7.5 \mathrm{~mm}$ where the temperature and mass fractions of $\mathrm{H}, \mathrm{CH}_{3}$, and $\mathrm{HO}_{2}$ are close to their peak values. Figure. 7 shows a small increase of fuel around $5 \mathrm{~mm}$ caused by thermal diffusion. The increase in temperature from the fuel boundary enhances diffusion of nitrogen relative to the fuel.

Figure 8 shows profiles of $Y_{\mathrm{OH}}$ for the three cases considered here. With increasing strain rate the small peak in the profile of $\mathrm{OH}$ disappears. This again indicates that strain has a greater influence than oxidizer temperature on low temperature chemistry.

\section{Concluding Remarks}

The short chemical-kinetic mechanism for $n$-heptane was assembled from the detailed mechanism of Curran et al. [10] without introducing any empirical approximation. This mechanism remains to be tested at pressures greater than 1 bar. It is still too large for application in 


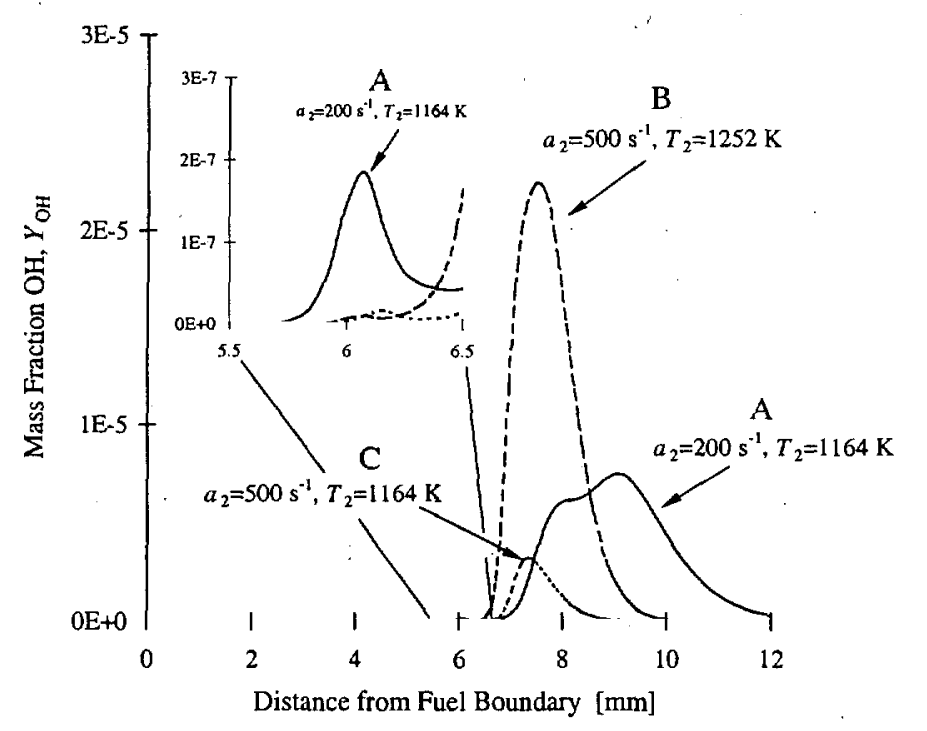

Figure 8: Profiles of the mass fraction of $\mathrm{OH}, Y_{\mathrm{OH}}$, calculated using the short mechanism for $Y_{\mathrm{F}, 1}=$ $0.387, T_{1}=378 \mathrm{~K}$, and $Y_{\mathrm{O}_{2}, 2}=0.233$.

computational fluid dynamic codes. To make such applications tractable it will be useful to derive reduced chemical-kinetic mechanisms made up of global steps from this short mechanism.

Aspects of autoignition can be described in terms of Damköhler number which is defined as the ratio of characteristic flow time, $\tau_{\mathrm{f}}$, to characteristic chemical time $\tau_{\mathrm{c}}$. In strained flows $\tau_{f}$ is given by the reciprocal of the strain rate. As strain rate increases $\tau_{f}$ decreases. If chemistry is described by a one-step reaction, $\tau_{c}$ is given by the rate constant of this reaction. The present investigation shows that at low strain rates there is sufficient time for both low temperature chemistry and high temperature chemistry to take place. At high strain rates there is insufficient time for low temperature chemistry to take place; autoignition is controlled by high temperature chemical processes. This is one of the fundamental differences between one-step chemistry and multiple-step chemistry.

\section{Acknowledgments}

The research at UCSD was supported by the U. S. Army Research Office through Grant \# DAAD19-99-1-0259, under the direction of David M. Mann. Part of this work was performed under the auspices of the U. S. Department of Energy by the Lawrence Livermore National Laboratory under the contract No. W-7405-ENG-48. 


\section{References}

[1] Warnatz J., Twentieth Symposium (International) on Combustion, The Combustion Institute, Pittsburgh, PA, 1984, pp. 845-856.

[2] Chevaliar C., Louessard P., Müller U.C., and Warnatz J., International Symposium on Diagnostics and Modelling of Combustion in Internal Engines, COMODIA 90, The Japan Society of Mechanical Engineers, Kyoto, Japan, 1990.

[3] Westbrook C.K., Warnatz J., and Pitz W.J., Twenty-Second Symposium (International) on Combustion, The Combustion Institute, Pittsburgh, Pennsylvania, 1988, pp. 893-901.

[4] Bui M. and Seshadri K., Combustion Science and Technology 79:293-310 (1991).

[5] Lindstedt R.P. and Maurice L.Q., Combustion Science and Technology 107:317-353 (1995).

[6] Ranzi E., Gaffuri P., Faravelli T., and Dagaut P., Combustion and Flame 103:91-106 (1995).

[7] Maurice L.Q., Detailed chemical kinetic models for aviation fuels, Ph.D thesis, The University of London, 1996.

[8] Bollig M., Pitsch H., Hewson J.C., and Seshadri K., Twenty-Sixth Symposium (International) on Combustion, The Combustion Institute, Pittsburgh, Pennsylvania, 1996, pp. 729-737.

[9] Held H.J., Marchese A.J., and Dryer F.L., Combustion Science and Technology 123:107146 (1997).

[10] Curran H.J., Gaffuri P., Pitz W.J., and Westbrook C.K., Combustion and Flame 114:149177 (1998).

[11] Lindstedt P., Twenty-Seventh Symposium (International) on Combustion, The Combustion Institute, Pittsburgh, Pennsylvania, 1998, in press.

[12] Seiser R., Truett L., Trees D., and Seshadri K., Twenty-Seventh Symposium (International) on Combustion, The Combustion Institute, Pittsburgh, Pennsylvania, 1998, pp. 649-657.

[13] Seiser R., Pitsch H., Seshadri K., Curran H.J., and Pitz W.J., Experimental and numerical studies of extinction and autoignition of n-heptane, paper presented at the Fall Meeting of the Western States Section of the Combustion Institute, The University of California at Irvine, Irvine, California, October 25, 26, 1999. 
[14] Seiser R., Seshadri K., Piskernik E., and Liñán A., Combustion and Flame Submitted for publication.

[15] Ciezki H.K. and Adomeit G., Combustion and Flame 93:421-433 (1993).

[16] Minetti R., Carlier M., Ribaucour M., Therssen E., and Sochet L.R., Combustion and Flame 102:298-309 (1995).

[17] Griffiths J.F., Halford-Maw P.A., and Rose D.J., Combustion and Flame 95:291-306 (1993).

[18] Griffiths J.F., Halford-Maw P.A., and Mohamed C., Combustion and Flame 111:327-337 (1997).

[19] Seshadri K. and Williams F.A., International Journal of Heat and Mass Transfer 21, 2:251-253 (1978).

[20] Peters N., Progress in Energy and Combustion Science 10:319-339 (1984).

[21] Peters N., Peters N. and Rogg B. (eds.), Reduced Kinetic Mechanisms for Applications in Combustion Systems, vol. m15 of Lecture Notes in Physics, Springer-Verlag, Heidelberg, 1993, chap. 1, pp. 1-13.

[22] Pitsch H., Entwicklung eines Programmpaketes zur Berechnung eindimensionaler Flammen am Beispiel einer Gegenstromdiffusionsflamme, Master's thesis, RWTH Aachen, Germany, 1993.

[23] Curran H.J., Gaffuri P., Pitz W.J., and Westbrook C.K., In preparation .

[24] Lay T. and Bozzelli J.W., Journal of Physical Chemistry A 101:9505-9510 (1997).

[25] Knyazev V.D. and Slagle I.R., Journal of Physical Chemistry A 102:1770-1778 (1998).

[26] Seiser R., Pitsch H., Seshadri K., Pitz W.J., and Curran H.J., Intermediate and short mechanism for n-heptane oxidation, www.combustion.ucsd.edu/mechanisms/heptane/28symposium. 